\title{
Genes and hormones of the hypothalamic-pituitary-adrenal axis in post-traumatic stress disorder. What is their role in symptom expression and treatment response?
}

\author{
Susanne Fischer ${ }^{1}$ DD $\cdot$ Tabea Schumacher $^{2} \cdot$ Christine Knaevelsrud $^{2} \cdot$ Ulrike Ehlert $^{1} \cdot$ Sarah Schumacher $^{2,3}$
}

Received: 12 February 2021 / Accepted: 22 March 2021 / Published online: 7 April 2021

(c) The Author(s) 2021

\begin{abstract}
Background Less than half of all individuals with post-traumatic stress disorder (PTSD) remit spontaneously and a large proportion of those seeking treatment do not respond sufficiently. This suggests that there may be subgroups of individuals who are in need of augmentative or alternative treatments. One of the most frequent pathophysiological findings in PTSD is alterations in the hypothalamic-pituitary-adrenal (HPA) axis, including enhanced negative feedback sensitivity and attenuated peripheral cortisol. Given the role of the HPA axis in cognition, this pattern may contribute to PTSD symptoms and interfere with key processes of standard first-line treatments, such as trauma-focused cognitive behavioural therapy (TF-CBT). Methods This review provides a comprehensive summary of the current state of research regarding the role of HPA axis functioning in PTSD symptoms and treatment.

Results Overall, there is preliminary evidence that hypocortisolaemia contributes to symptom manifestation in PTSD; that it predicts non-responses to TF-CBT; and that it is subject to change in parallel with positive treatment trajectories. Moreover, there is evidence that genetic and epigenetic alterations within the genes NR3C1 and FKBP5 are associated with this hypocortisolaemic pattern and that some of these alterations change as symptoms improve over the course of treatment. Conclusions Future research priorities include investigations into the role of the HPA axis in day-to-day symptom variation, the time scale in which biological changes in response to treatment occur, and the effects of sex. Furthermore, before conceiving augmentative or alternative treatments that target the described mechanisms, multilevel studies are warranted.
\end{abstract}

Keywords Cognitive behavioural therapy $\cdot$ Cortisol $\cdot$ Methylation $\cdot$ Post-traumatic stress disorder $\cdot$ Psychotherapy

\section{Introduction}

Post-traumatic stress disorder (PTSD) is a pathological response to a traumatic event involving exposure to actual or threatened death, serious injury, or sexual violation (APA 2013). The prevalence rate of PTSD lies at $2.3 \%$, with a clear female preponderance $(3.6 \%$ vs. $0.9 \%$ in men; Jacobi et al.

Susanne Fischer

s.fischer@psychologie.uzh.ch

1 Institute of Psychology, Clinical Psychology and Psychotherapy, University of Zurich, Binzmuehlestrasse 14/Box 26, 8050 Zurich, Switzerland

2 Department of Education and Psychology, Division of Clinical Psychological Intervention, Freie Universität Berlin, Berlin, Germany

3 Health Faculty, Clinical Psychology and Psychotherapy, Health and Medical University Potsdam, Potsdam, Germany
2014). The twelve-month incidence rate is particularly high after interpersonal trauma, with $37.5 \%$ of individuals developing PTSD after being raped and $35.5 \%$ following sexual abuse during childhood, compared to $6.9 \%$ after witnessing traffic accidents or violence (Maercker et al. 2008). Individuals affected by PTSD experience a wide range of distressing symptoms, such as flashbacks, negative affect and thoughts, feelings of isolation, and difficulties concentrating or sleeping (APA 2013). The experience of such symptoms is known to impair one's ability to participate in social activities or relationships (Geisser et al. 1996) or to work regularly (Matthews 2005; Smith et al. 2005), and the risk of suicidal behaviours is increased two- to three-fold in this population (Kanwar et al. 2013; Bentley et al. 2016). Moreover, PTSD exerts a significant economic burden on society. In Europe alone, the annual healthcare costs are estimated at 8.4 billion Euros, with 7.7 million individuals currently affected (Gustavsson et al. 2011). 
As shown in a meta-analysis, on average, only $44 \%$ of individuals with PTSD remit spontaneously after more than 3 years (Morina et al. 2014). Fortunately, a number of treatments are readily available to prevent chronic illness trajectories. Among these, trauma-focused cognitive behavioural therapy (TF-CBT) is the gold standard for PTSD (Lee et al. 2016). It comprises behavioural interventions, such as prolonged exposure to traumatic cues or memories (Foa 2007), as well as cognitive interventions, such as the cognitive restructuring of dysfunctional trauma-related beliefs (Resick et al. 2007). Given that PTSD often affects individuals with limited access to such treatments (e.g., less mobile elderly people, rural populations), there has been a growing interest in internet-based administrations of such treatments. These are usually therapist-guided, and have been shown to be effective in numerous different populations, such as patients who have suffered pregnancy loss, intimate partner violence, or rape (see Sijbrandij et al. 2016; Kuester et al. 2016 for meta-analyses). However, despite the general effectiveness of both face-to-face and internet-based TF-CBT, some studies have reported substantial non-responder rates (Ponniah and Hollon 2009). This implies that a large proportion of patients with PTSD remain symptomatic, with an increased risk of a chronic progression of the disorder.

A crucial first step towards the prevention of a protracted course of the disorder is to identify factors that contribute to PTSD perpetuation and non-responses to standard firstline treatments. The most frequently studied candidate factors to date are PTSD symptom severity, trauma type, and comorbidity with other mental disorders (Schottenbauer et al. 2008; Morina et al. 2014). The problem with these clinical characteristics is that they are limited in their ability to shed light on why PTSD persists in some individuals but not in others. However, evidence illuminating the mechanisms underlying this phenomenon is now beginning to accumulate.

\section{Hypothalamic-pituitary-adrenal axis functioning}

Post-traumatic stress disorder has been found to present with alterations across various neurobiological systems (Yehuda 2002). Given its aetiology, a major research focus has been on the stress-responsive hypothalamic-pituitary-adrenal (HPA) axis and its end product, the glucocorticoid cortisol (Ehlert et al. 2001). Cortisol can be measured non-invasively by repeated saliva sampling at fixed time points over the course of at least two consecutive days (Stalder et al. 2016). Five meta-analyses have provided evidence that a substantial subgroup of individuals with PTSD are characterised by hypocortisolism, that is, reduced levels of cortisol (Morris et al. 2012; Meewisse et al. 2007; Schumacher et al. 2019;
Pan et al. 2018, 2020). A common explanation for this phenomenon is an enhanced negative feedback sensitivity (Daskalakis et al. 2013). This means that the glucocorticoid receptors (GR), which are expressed at the hypothalamic and pituitary level, are more responsive to the effects of cortisol reaching the brain, thus leading to a stronger-than-usual inhibition of the HPA axis. An important co-chaperone of glucocorticoid sensitivity is the FK506 binding protein 5 (FKBP5), which reduces the GR's affinity to cortisol.

Importantly, this hypocortisolaemic pattern does not appear to be a mere consequence of PTSD but most likely represents a key factor underlying its development and maintenance. This is due to the key role of cortisol in fear conditioning. Numerous studies have demonstrated that cortisol facilitates the consolidation of fear memories, while at the same time impeding their retrieval (de Quervain et al. 2017). Acute increases in cortisol during traumatic situations thus support the transfer of short-term fear memories into longterm fear memories. This effect depends on the concomitant activation of the central noradrenergic system and occurs via non-genomic and genomic effects within the amygdala, hippocampus, and cortex. Following this initial consolidation, it is assumed that in some individuals, the initially elevated cortisol concentrations decrease overtime via hypersensitisation of GR (Steudte-Schmiedgen et al. 2016), resulting in the hypocortisolaemic pattern as described above. In the same individuals, a failure of cortisol to inhibit the retrieval of fear memories may then contribute to chronic re-experiencing of traumatic situations (e.g., via flashbacks). Indeed, the administration of hydrocortisone, a synthetic analogue of cortisol, has been found to reduce PTSD symptoms and incidence when administered in a preventive context (Kothgassner et al. 2021). Furthermore, in individuals with PTSD, negative associations of cortisol with symptoms of intrusion, as well as with symptoms of avoidance, numbing, and hyper-arousal, have repeatedly been reported (CastroVale et al. 2016). Given that these symptoms fluctuate both within and across days (e.g., Biggs et al. 2019; Schuler et al. 2019), an important question that remains to be answered is whether low cortisol levels also contribute to PTSD symptom exacerbation.

As the extinction of fear memories is a main goal of TF-CBT, a further question is whether cortisol levels modulate treatment response. There is evidence to suggest that this is indeed the case. In patients with anxiety disorders, lower cortisol during exposure therapy sessions appears to be linked to poorer responses to CBT (Fischer and Cleare 2017). As outlined in the previous paragraph, this may be explained by the fact that failure to mount and maintain sufficiently high cortisol levels during exposure to phobic stimuli prevents the consolidation of an extinction memory, which is integral to the treatment of any fear-related pathology. In PTSD, only a small number of 
studies have investigated pre-treatment cortisol in terms of predicting outcomes after TF-CBT (Schumacher et al. 2018). A higher cortisol awakening response (CAR) (Rapcencu et al. 2017) and a more suppressed CAR after dexamethasone intake (Nijdam et al. 2015) were found to predict greater symptom improvements. Furthermore, some studies revealed changes in cortisol as a result of treatment response. However, the direction of these changes remained ambiguous, with increases (Olff et al. 2007) as well as decreases (Gerardi et al. 2010) being observed.
In sum, the current state of research indicates that at least a subgroup of individuals with PTSD presents with increased GR sensitivity, which is reflected by a hypocortisolaemic pattern. Preliminary evidence suggests that this pattern contributes to the manifestation of PTSD symptoms (see Fig. 1). Moreover, the same pattern may predict nonresponses to TF-CBT due to its interference with the formation of an extinction memory-and may be subject to change in parallel with positive treatment trajectories (see Fig. 2, first panel). This raises the question as to where this pattern originates in the first place.

GENETICS

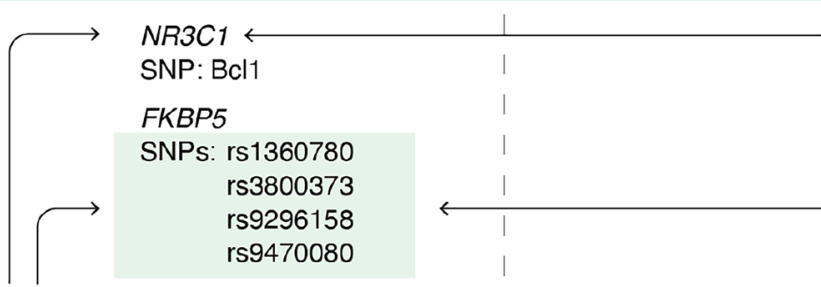

EPIGENETICS

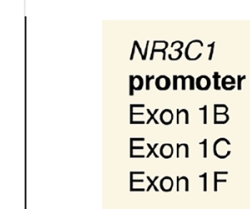

CORTISOL

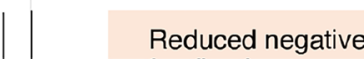

feedback

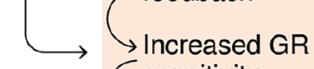

sensitivity

$\longrightarrow$ Hypocortisolaemia

MEMORY PROCESSES
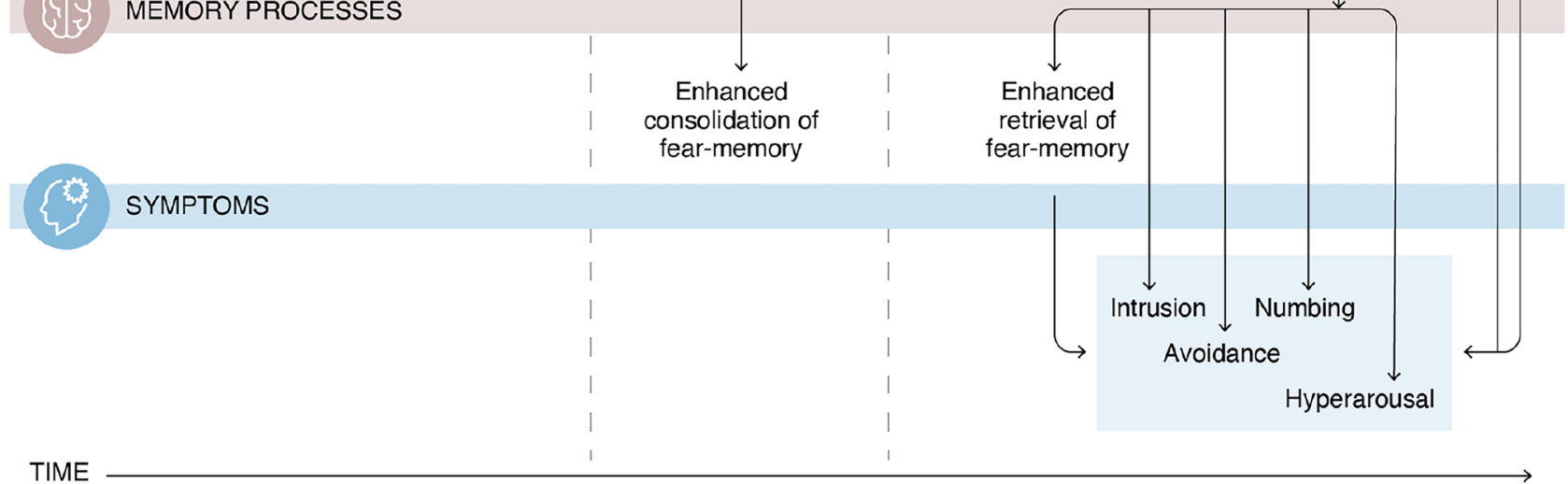

Fig. 1 Illustration of hypothalamic-pituitary-adrenal (HPA) axis related (epi-)genetic and endocrine findings in posttraumatic stress disorder (PTSD). The current state of research suggests that at least a subgroup of individuals with PTSD presents with a number of single nucleotide polymorphisms and DNA methylation patterns that are associated with altered HPA axis functioning, such as increased glucocorticoid receptor (GR) sensitivity and hypocortisolaemia. These characteristics may directly contribute to the manifestation of PTSD symptoms via disturbed memory processes. University of Zurich, Information Technology, MELS/SIVIC, Tara von Grebel 

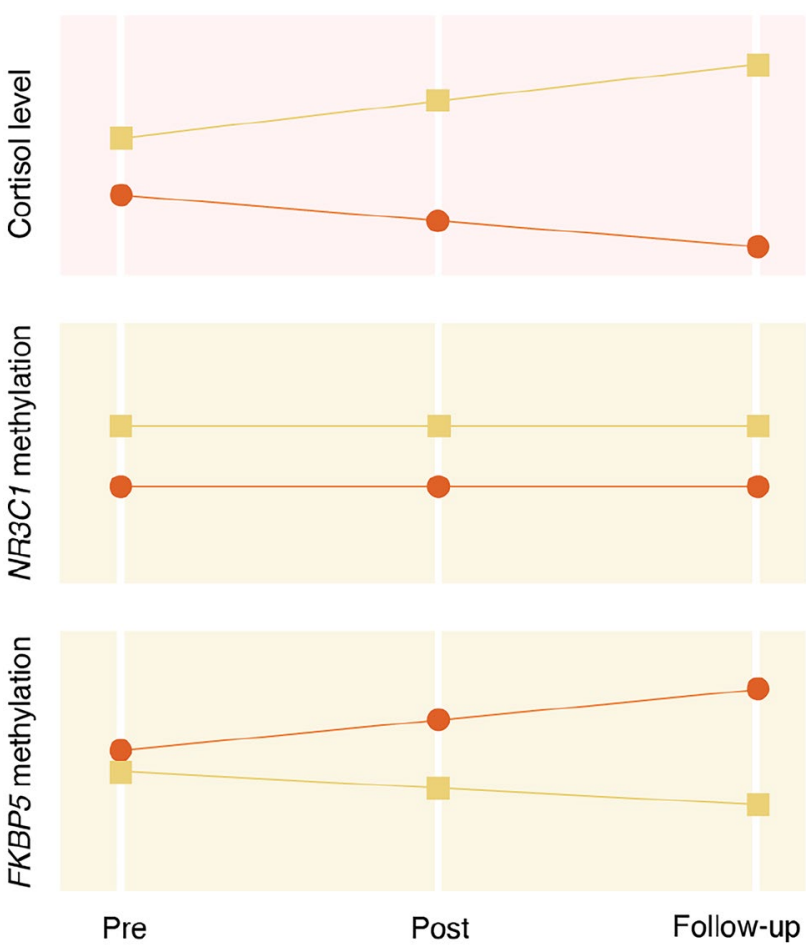

Fig. 2 Illustration of the hypothesised relationship between hypothalamic-pituitary-adrenal axis related (epi-)genetic and endocrine markers and trauma-focused cognitive behavioural therapy (TF-CBT) for posttraumatic stress disorder (PTSD). "Pre" refers to the pre-treatment assessment, "post" to the post-treatment assessment, and "follow-up" to the follow-up assessment. Non-responders are indicated in red and responders are indicated in yellow. According to the current state of research, low levels of cortisol and high levels of $\mathrm{NR} 3 \mathrm{Cl}$ methylation are likely to predict non-responses to TF-CBT. Furthermore, cortisol levels presumably increase and FKBP5 methylation decreases in parallel with positive treatment trajectories. University of Zurich, Information Technology, MELS/SIVIC, Tara von Grebel

\section{Genetic underpinnings-single nucleotide polymorphisms}

The heritability of PTSD is estimated at between 30 and $70 \%$ (Daskalakis et al. 2018), and a number of genes known to encode different components of the HPA axis appear to be partly responsible for this. According to a systematic review of the literature, the $\mathrm{Bcl} 1$ single nucleotide polymorphism (SNP) within $\mathrm{NR} 3 \mathrm{Cl}$ and four SNPs within FKBP5 (rs1360780, rs3800373, rs9296158, rs9470080) are particularly prominent HPA axis related risk factors for the development of PTSD (Carvalho et al. 2017). A recent meta-analysis confirmed the role of $N R 3 C 1$ and FKBP5 in PTSD, with rs258747 and rs9296158 emerging as significant risk-enhancing SNPs (Sheerin et al. 2020). The fact that $N R 3 C 1$ is the gene encoding the GR while FKBP5 is the gene encoding the protein of the same name resonates well with the above-outlined pathophysiological mechanism in
PTSD (i.e., increased GR sensitivity). In line with this, one study found that the Bcl1 SNP within NR3Cl was linked not only to post-traumatic symptoms but also to lower cortisol levels (Hauer et al. 2011). Similarly, rs1360780, rs3800373, rs9296158, and rs 9470080 within FKBP5 predicted both a diagnosis of PTSD and enhanced negative feedback sensitivity (Binder et al. 2008). The latter finding was complemented by further studies revealing an association of the same SNPs with cortisol (Sarapas et al. 2011; Young et al. 2018), which was mediated by FKBP5 expression (Sarapas et al. 2011). Together, these findings support the notion that individuals with a particular genetic background are more vulnerable to develop (and maintain) PTSD when faced with trauma over the course of their lifespan, and that this may occur via a functional impact of specific SNPs linked to the HPA axis.

In recent years, two studies have complemented this research by testing whether the same SNPs were predictors of treatment outcomes. In a sample of $N=52$ war veterans with PTSD, Yehuda et al. (2014) found that those patients who were homozygous carriers of the $\mathrm{Bcl1} \mathrm{C}$ allele $(\mathrm{NR} 3 \mathrm{Cl}$ ) were more likely to be non-responders to twelve weeks of prolonged exposure or minimal attention intervention. Focusing instead on FKBP5, Wilker et al. (2014) investigated $N=43$ survivors of the rebel war in Northern Uganda and found that carriers of the rs $1360780 \mathrm{~T}$ allele had worse long-term outcomes after 6 weeks of narrative exposure therapy. Notably, in the former study the treatment arms were collapsed for statistical analysis and the latter study only reported results for the follow-up assessments. Interestingly, the vast majority of studies published to date showed that the four SNPs within FKBP5 mentioned above interact with childhood trauma and other environmental stressors in enhancing PTSD risk (see Wang et al. 2018 for meta-analyses; Hawn et al. 2019). The question thus arises whether environmentally induced modifications to the genome coregulating gene expression could contribute to PTSD symptoms and treatment response.

\section{Epigenetic underpinnings-DNA methylation}

Epigenetic research into PTSD has recently gained momentum (Zannas et al. 2015). Although not representing changes to the genetic code, epigenetic signatures, such as levels of DNA methylation or histone acetylation, are relatively stable and can be inherited. However, modifications to the epigenome can occur due to environmental influences. DNA methylation in particular has attracted researchers' attention since reports of demonstrable changes in the aftermath of childhood trauma (e.g., McGowan et al. 2009), and because it can be measured reliably in a number of tissues. 
In brief, DNA methylation refers to the process of methyl molecules attaching to the $5^{\prime}$ carbon position of cytosine residues within $\mathrm{CpG}$ dinucleotides. Within $\mathrm{NR} 3 \mathrm{Cl}$ and $F K B P 5$, methylation levels are particularly variable in promoter regions, which regulate gene expression and where a number of glucocorticoid-responsive elements are located (Zannas et al. 2015). In PTSD, alterations in DNA methylation have so far been documented within the exon 1B, 1C, and 1F NR3C1 promoter regions (Labonte et al. 2014; Vukojevic et al. 2014; Yehuda et al. 2015; Schechter et al. 2015). Again, patients not only exhibited lower methylation levels when compared to controls, but these were directly related to enhanced negative feedback sensitivity and lower cortisol concentrations (Yehuda et al. 2015; Labonte et al. 2014). It therefore seems that besides the genetic make-up, epigenetic signatures are equally relevant in HPA axis functioning in PTSD.

Only two studies to date have tested whether methylation within HPA axis-relevant genes is related to treatment responses in PTSD. In a sample of $N=16$ war veterans, Yehuda et al. (2013) found that lower pre-treatment methylation of the $\mathrm{NR} 3 \mathrm{Cl}$ exon $1 \mathrm{~F}$ promoter region was linked to poorer responses to TF-CBT. Additionally, positive outcomes were paralleled by decreases in methylation of the FKBP5 exon 1 promoter region over the course of treatment. In a more recent study, Bishop et al. (2018) reported that changes in methylation of the FKBP5 intron 7 region interacted with responder status after mindfulness-based stress reduction for veterans with PTSD. More specifically, the authors observed significant decreases in methylation in treatment responders $(n=11)$ and increases in methylation in non-responders $(n=11)$. The latter results suggest that methylation of FKBP5 is malleable in that short-term changes due to environmental influences (i.e., TF-CBT) may occur. In line with this, it was found that methylation levels of intron 7 within $F K B P 5$ decreased over the course of only one week in $\mathrm{N}=34$ healthy university students undergoing stress management training (Stoffel et al. 2017, 2020).

Taken together, methylation of $\mathrm{NR} 3 \mathrm{Cl}$ may thus be considered as a prognostic marker of TF-CBT response, while methylation of $F K B P 5$ may be considered as a marker of symptom change (see also Fig. 2, second and third panel).

\section{Conclusions}

In sum, the current state of research suggests that both genetic and epigenetic markers within NR3Cl and FKBP5 are associated with the observed hypocortisolaemic pattern as frequently present in PTSD and preliminary evidence suggests that the same markers are indicative of treatment outcomes. However, a number of gaps are still apparent in this literature and should be addressed by future research.

First, despite evidence from laboratory studies that cortisol levels are associated with PTSD symptom severity, it currently remains unknown whether diurnal changes in cortisol levels map onto PTSD symptom exacerbation in daily life. In other research domains such as depression, initial studies have, for instance, demonstrated a positive correlation between daily cortisol levels and rumination (Huffziger et al. 2013). Knowing more about the extent to which cortisol contributes to symptom exacerbation may not only provide further evidence for a role of cortisol in the pathophysiology of PTSD, but may also help patients to manage their symptoms by deliberately engaging in activities that are capable of adjusting cortisol, such as stress management strategies (Hammerfald et al. 2006) or Hatha yoga (Benvenutti et al. 2017). Similarly, large-scale prospective studies that allow the temporal order between HPA axis disturbances and PTSD incidence to be established are warranted in order to confirm that such alterations are integral to the symptom development rather than a mere consequence of being chronically ill.

Second, there is no data on the long-term trajectory of cortisol after patients have undergone TF-CBT. Collecting such data could be important since a number of studies in depression and anxiety disorders have reported significant changes in cortisol at follow-up rather than at the end of treatment (Fischer and Zilcha-Mano under review; Laufer et al. 2018), indicating that therapeutic changes in biological systems may emerge with a time delay. Supporting this notion, a recent study in patients with anxiety disorders provided initial evidence that pre- to post-treatment changes in FKBP5 methylation were strongly associated with treatment outcome at six-month follow-up but not at post-treatment (Roberts et al. 2019). Future studies aiming to illuminate the interaction of HPA axis functioning at the genetic, epigenetic and endocrine level with treatment response should monitor potential changes beyond psychotherapeutic treatment, i.e., by including follow-up assessments. Moreover, these followup assessments should be conducted at multiple time points to enhance the understanding of the time frame in which alterations occur.

Third, all (epi-)genetic studies have exclusively studied war-related PTSD, and in relation to this have almost exclusively examined men. As such, it is unclear whether the findings extend to women, who are not only more frequently affected by PTSD but are also more likely to be exposed to other types of trauma (e.g., sexual assault). Further studies are thus necessary to extend these important findings to women samples. In addition, it might be worthwhile to explore the impact of sex hormones on the development and maintenance of PTSD symptoms. Indeed, psychotherapy 
studies in the context of anxiety disorders have already demonstrated that sex hormone concentrations affect treatment outcomes (Graham et al. 2018). Given that TF-CBT is based on the same principles as gold standard treatments for anxiety disorders (i.e., fear extinction), it is conceivable that the same effects might be observable in PTSD.

Nevertheless, when taken together, it is feasible that a subset of individuals with PTSD, namely those with a specific genetic make-up and epigenetic alterations within HPA axis-relevant genes, present with a hypocortisolaemic pattern and more persistent PTSD symptoms that do not improve sufficiently after TF-CBT. Initial attempts at augmenting TF-CBT by administering glucocorticoids to patients with PTSD have already been undertaken (see e.g. de Quervain et al. 2017). Likewise, the development of drugs targeting epigenetic alterations in PTSD is conceivable and has begun to be implemented in animals (e.g., drugs targeting DNA methyltransferases, Zannas et al. 2015); however, this needs to be preceded by a more comprehensive understanding of the role of these processes in PTSD. Multilevel studies, that is, studies which integrate markers of the HPA axis at the genetic, epigenetic, and endocrine level, are essential in order to achieve a comprehensive characterisation of the proposed subgroup.

Funding Open Access funding provided by Universität Zürich.. This manuscript has been prepared as part of a scientific collaboration between SF and SSch, which was supported by Seed Money Funding from the Freie Universität Berlin and the University of Zurich, a Peer Mentoring Award from the German Society for Behavioural Medicine (DGVM), and a Young Investigator Colloquium scholarship of the American Psychosomatic Society (APS).

\section{Declarations}

Conflict of interest The authors declare that they have no conflict of interest.

Open Access This article is licensed under a Creative Commons Attribution 4.0 International License, which permits use, sharing, adaptation, distribution and reproduction in any medium or format, as long as you give appropriate credit to the original author(s) and the source, provide a link to the Creative Commons licence, and indicate if changes were made. The images or other third party material in this article are included in the article's Creative Commons licence, unless indicated otherwise in a credit line to the material. If material is not included in the article's Creative Commons licence and your intended use is not permitted by statutory regulation or exceeds the permitted use, you will need to obtain permission directly from the copyright holder. To view a copy of this licence, visit http://creativecommons.org/licenses/by/4.0/.

\section{References}

APA (2013) Diagnostic and Statistical Manual of Mental Disorders (5th edition). APA, Washington D.C.
Bentley KH, Franklin JC, Ribeiro JD, Kleiman EM, Fox KR, Nock MK (2016) Anxiety and its disorders as risk factors for suicidal thoughts and behaviors: a meta-analytic review. Clin Psychol Rev 43:30-46

Benvenutti MJ, Alves EDS, Michael S, Ding D, Stamatakis E, Edwards KM (2017) A single session of hatha yoga improves stress reactivity and recovery after an acute psychological stress task-A counterbalanced, randomized-crossover trial in healthy individuals. Complement Ther Med 35:120-126

Biggs QM, Ursano RJ, Wang J, Krantz DS, Carr RB, Wynn GH, Adams DP, Dacuyan NM, Fullerton CS (2019) Daily variation in post traumatic stress symptoms in individuals with and without probable post traumatic stress disorder. BMC Psychiatry 19:56

Binder EB, Bradley RG, Liu W, Epstein MP, Deveau TC, Mercer KB, Tang Y, Gillespie CF, Heim CM, Nemeroff CB, Schwartz AC, Cubells JF, Ressler KJ (2008) Association of FKBP5 polymorphisms and childhood abuse with risk of posttraumatic stress disorder symptoms in adults. JAMA 299:1291-1305

Bishop JR, Lee AM, Mills LJ, Thuras PD, Eum S, Clancy D, Erbes CR, Polusny MA, Lamberty GJ, Lim KO (2018) Methylation of FKBP5 and SLC6A4 in relation to treatment response to mindfulness based stress reduction for posttraumatic stress disorder. Front Psychiatry 9:418

Carvalho CM, Coimbra BM, Ota VK, Mello MF, Belangero SI (2017) Single-nucleotide polymorphisms in genes related to the hypothalamic-pituitary-adrenal axis as risk factors for posttraumatic stress disorder. Am J Med Genet B Neuropsychiatr Genet 174:671-682

Castro-Vale I, van Rossum EF, Machado JC, Mota-Cardoso R, Carvalho D (2016) Genetics of glucocorticoid regulation and posttraumatic stress disorder-What do we know? Neurosci Biobehav Rev 63:143-157

Daskalakis NP, Lehrner A, Yehuda R (2013) Endocrine aspects of post-traumatic stress disorder and implications for diagnosis and treatment. Endocrinol Metab Clin North Am 42:503-513

Daskalakis NP, Rijal CM, King C, Huckins LM, Ressler KJ (2018) Recent genetics and epigenetics approaches to PTSD. Curr Psychiatry Rep 20:30

de Quervain D, Schwabe L, Roozendaal B (2017) Stress, glucocorticoids and memory: implications for treating fear-related disorders. Nat Rev Neurosci 18:7-19

Ehlert U, Gaab J, Heinrichs M (2001) Psychoneuroendocrinological contributions to the etiology of depression, posttraumatic stress disorder, and stress-related bodily disorders: the role of the hypothalamus-pituitary-adrenal axis. Biol Psychol 57(1-3):141-152. https://doi.org/10.1016/s0301-0511(01)00092-8

Fischer S, Cleare AJ (2017) Cortisol as a predictor of psychological therapy response in anxiety disorders-systematic review and metaanalysis. J Anxiety Disord 47:60-68

Fischer S, Zilcha-Mano S (under review) Why does psychotherapy work and for whom? Hormonal answers.

Foa EB (2007) Prolonged exposure therapy for ptsd: emotional processing of traumatic experiences. Oxford University Press, New York, NY, Therapist Guide

Geisser ME, Roth RS, Bachman JE, Eckert TA (1996) The relationship between symptoms of post-traumatic stress disorder and pain, affective disturbance and disability among patients with accident and non-accident related pain. Pain 66:207-214

Gerardi M, Rothbaum BO, Astin MC, Kelley M (2010) Cortisol response following exposure treatment for PTSD in rape victims. J Aggr Maltr Trauma 19:349-356

Graham BM, Li SH, Black MJ, Ost LG (2018) The association between estradiol levels, hormonal contraceptive use, and responsiveness to one-session-treatment for spider phobia in women. Psychoneuroendocrinology 90:134-140

Gustavsson A, Svensson M, Jacobi F, Allgulander C, Alonso J, Beghi E, Dodel R, Ekman M, Faravelli C, Fratiglioni L, Gannon B, Jones 
DH, Jennum P, Jordanova A, Jonsson L, Karampampa K, Knapp M, Kobelt G, Kurth T, Lieb R, Linde M, Ljungcrantz C, Maercker A, Melin B, Moscarelli M, Musayev A, Norwood F, Preisig M, Pugliatti M, Rehm J, Salvador-Carulla L, Schlehofer B, Simon R, Steinhausen HC, Stovner LJ, Vallat JM, Van den Bergh P, van Os J, Vos P, Xu W, Wittchen HU, Jonsson B, Olesen J, Group CD (2011) Cost of disorders of the brain in Europe 2010. Eur Neuropsychopharmacol 21(10):718-779

Hammerfald K, Eberle C, Grau M, Kinsperger A, Zimmermann A, Ehlert U, Gaab J (2006) Persistent effects of cognitive-behavioral stress management on cortisol responses to acute stress in healthy subjects-a randomized controlled trial. Psychoneuroendocrinology 31:333-339

Hauer D, Weis F, Papassotiropoulos A, Schmoeckel M, Beiras-Fernandez A, Lieke J, Kaufmann I, Kirchhoff F, Vogeser M, Roozendaal B, Briegel J, de Quervain D, Schelling G (2011) Relationship of a common polymorphism of the glucocorticoid receptor gene to traumatic memories and posttraumatic stress disorder in patients after intensive care therapy. Crit Care Med 39:643-650

Hawn SE, Sheerin CM, Lind MJ, Hicks TA, Marraccini ME, Bountress K, Bacanu SA, Nugent NR, Amstadter AB (2019) GxE effects of FKBP5 and traumatic life events on PTSD: a meta-analysis. J Affect Disord 243:455-462

Huffziger S, Ebner-Priemer U, Zamoscik V, Reinhard I, Kirsch P, Kuehner C (2013) Effects of mood and rumination on cortisol levels in daily life: an ambulatory assessment study in remitted depressed patients and healthy controls. Psychoneuroendocrinology 38:2258-2267

Jacobi F, Hofler M, Strehle J, Mack S, Gerschler A, Scholl L, Busch MA, Maske U, Hapke U, Gaebel W, Maier W, Wagner M, Zielasek J, Wittchen HU (2014) Mental disorders in the general population. Study on the health of adults in Germany and the additional module mental health (DEGS1-MH). Nervenarzt 85:77-87

Kanwar A, Malik S, Prokop LJ, Sim LA, Feldstein D, Wang Z, Murad MH (2013) The association between anxiety disorders and suicidal behaviors: a systematic review and meta-analysis. Depress Anxiety 30:917-929

Kothgassner OD, Pellegrini M, Goreis A, Giordano V, Edobor J, Fischer S, Plener PL, Huscsava MM (2021) Hydrocortisone administration for reducing post-traumatic stress symptoms: a systematic review and meta-analysis. Psychoneuroendocrinology 126:105168

Kuester A, Niemeyer H, Knaevelsrud C (2016) Internet-based interventions for posttraumatic stress: a meta-analysis of randomized controlled trials. Clin Psychol Rev 43:1-16

Labonte B, Azoulay N, Yerko V, Turecki G, Brunet A (2014) Epigenetic modulation of glucocorticoid receptors in posttraumatic stress disorder. Transl Psychiatry 4:e368

Laufer S, Engel S, Knaevelsrud C, Schumacher S (2018) Cortisol and alpha-amylase assessment in psychotherapeutic intervention studies: a systematic review. Neurosci Biobehav Rev 95:235-262

Lee DJ, Schnitzlein CW, Wolf JP, Vythilingam M, Rasmusson AM, Hoge CW (2016) Psychotherapy versus pharmacotherapy for posttraumatic stress disorder: systemic review and meta-analyses to determine first-line treatments. Depress Anxiety 33:792-806

Maercker A, Forstmeier S, Wagner B, Brähler E, Glaesmer H (2008) Posttraumatische Belastungsstörungen in Deutschland: Ergebnisse einer gesamtdeutschen epidemiologischen Untersuchung. Nervenarzt 5:577-586

Matthews LR (2005) Work potential of road accident survivors with post-traumatic stress disorder. Behav Res Ther 43:475-483

McGowan PO, Sasaki A, D'Alessio AC, Dymov S, Labonte B, Szyf M, Turecki G, Meaney MJ (2009) Epigenetic regulation of the glucocorticoid receptor in human brain associates with childhood abuse. Nat Neurosci 12:342-348
Meewisse ML, Reitsma JB, de Vries GJ, Gersons BP, Olff M (2007) Cortisol and post-traumatic stress disorder in adults: systematic review and meta-analysis. Br J Psychiatry 191:387-392

Morina N, Wicherts JM, Lobbrecht J, Priebe S (2014) Remission from post-traumatic stress disorder in adults: a systematic review and meta-analysis of long term outcome studies. Clin Psychol Rev 34:249-255

Morris MC, Compas BE, Garber J (2012) Relations among posttraumatic stress disorder, comorbid major depression, and HPA function: a systematic review and meta-analysis. Clin Psychol Rev 32:301-315

Nijdam MJ, van Amsterdam JG, Gersons BP, Olff M (2015) Dexamethasone-suppressed cortisol awakening response predicts treatment outcome in posttraumatic stress disorder. J Affect Disord 184:205-208

Olff M, de Vries GJ, Guzelcan Y, Assies J, Gersons BP (2007) Changes in cortisol and DHEA plasma levels after psychotherapy for PTSD. Psychoneuroendocrinology 32:619-626

Pan X, Wang Z, Wu X, Wen SW, Liu A (2018) Salivary cortisol in post-traumatic stress disorder: a systematic review and metaanalysis. BMC Psychiatry 18:324

Pan X, Kaminga AC, Wen SW, Wang Z, Wu X, Liu A (2020) The 24-hour urinary cortisol in post-traumatic stress disorder: a metaanalysis. PLoS ONE 15:e0227560

Ponniah K, Hollon SD (2009) Empirically supported psychological treatments for adult acute stress disorder and posttraumatic stress disorder: a review. Depress Anxiety 26:1086-1109

Rapcencu AE, Gorter R, Kennis M, van Rooij SJH, Geuze E (2017) Pre-treatment cortisol awakening response predicts symptom reduction in posttraumatic stress disorder after treatment. Psychoneuroendocrinology 82:1-8

Resick PA, Monson CM, Chard KM (2007) Cognitive processing therapy: veteran/military version. Department of Veterans' Affairs, Washington, DC

Roberts S, Keers R, Breen G, Coleman JRI, Jöhren P, Kepa A, Lester KJ, Margraf J, Scheider S, Teismann T, Wannemüller A, Eley TC, Wong CCY (2019) DNA methylation of FKBP5 and response to exposure-based psychological therapy. Am J Med Genet B Neuropsychiatr Genet 180:150-158

Sarapas C, Cai G, Bierer LM, Golier JA, Galea S, Ising M, Rein T, Schmeidler J, Muller-Myhsok B, Uhr M, Holsboer F, Buxbaum JD, Yehuda R (2011) Genetic markers for PTSD risk and resilience among survivors of the World Trade Center attacks. Dis Markers 30:101-110

Schechter DS, Moser DA, Paoloni-Giacobino A, Stenz L, Gex-Fabry M, Aue T, Adouan W, Cordero MI, Suardi F, Manini A, Sancho Rossignol A, Merminod G, Ansermet F, Dayer AG, Rusconi Serpa S (2015) Methylation of NR3C1 is related to maternal PTSD, parenting stress and maternal medial prefrontal cortical activity in response to child separation among mothers with histories of violence exposure. Front Psychol 6:690

Schottenbauer MA, Glass CR, Arnkoff DB, Tendick V, Gray SH (2008) Nonresponse and dropout rates in outcome studies on PTSD: review and methodological considerations. Psychiatry 71:134-168

Schuler K, Ruggero CJ, Mahaffey B, Gonzalez A, Callahan JL, Boals A, Waszczuk MA, Luft BJ, Kotov R (2021) When hindsight is not 20/20: ecological momentary assessment of PTSD symptoms versus retrospective report. Assessment 28:238-247

Schumacher S, Niemeyer H, Engel S, Cwik JC, Knaevelsrud C (2018) Psychotherapeutic treatment and HPA axis regulation in posttraumatic stress disorder: a systematic review and meta-analysis. Psychoneuroendocrinology 98:186-201

Schumacher S, Niemeyer H, Engel S, Cwik JC, Laufer S, Klusmann $\mathrm{H}$, Knaevelsrud C (2019) HPA axis regulation in posttraumatic 
stress disorder: a meta-analysis focusing on potential moderators. Neurosci Biobehav Rev 100:35-57

Sheerin CM, Lind MJ, Bountress KE, Marraccini ME, Amstadter AB, Bacanu SA, Nugent NR (2020) Meta-analysis of associations between hypothalamic-pituitary-adrenal axis genes and risk of posttraumatic stress disorder. J Trauma Stress 33:688-698

Sijbrandij M, Kunovski I, Cuijpers P (2016) Effectiveness of internetdelivered cognitive behavioral therapy for posttraumatic stress disorder: a systematic review and meta-analysis. Depress Anxiety 33:783-791

Smith MW, Schnurr PP, Rosenheck RA (2005) Employment outcomes and PTSD symptom severity. Ment Health Serv Res 7:89-101

Stalder T, Kirschbaum C, Kudielka BM, Adam EK, Pruessner JC, Wust S, Dockray S, Smyth N, Evans P, Hellhammer DH, Miller R, Wetherell MA, Lupien SJ, Clow A (2016) Assessment of the cortisol awakening response: expert consensus guidelines. Psychoneuroendocrinology 63:414-432

Steudte-Schmiedgen S, Kirschbaum C, Alexander N, Stalder T (2016) An integrative model linking traumatization, cortisol dysregulation and posttraumatic stress disorder: insight from recent hair cortisol findings. Neurosci Biobehav Rev 69:124-135

Stoffel M, Gardini E, Ehlert U, Ditzen B (2017) Alterations in DNA methylation of FKBP5 following a stress prevention program. Psychoneuroendocrinology 83:45

Stoffel M, Gardini E, Ehrenthal JC, Abbruzzese E, Ditzen B (2020) Evaluation of stress management and stress prevention using epigenetic markers. Verhaltenstherapie 30:18-27

Vukojevic V, Kolassa IT, Fastenrath M, Gschwind L, Spalek K, Milnik A, Heck A, Vogler C, Wilker S, Demougin P, Peter F, Atucha E, Stetak A, Roozendaal B, Elbert T, Papassotiropoulos A, de Quervain DJ (2014) Epigenetic modification of the glucocorticoid receptor gene is linked to traumatic memory and posttraumatic stress disorder risk in genocide survivors. J Neurosci 34:10274-10284

Wang Q, Shelton RC, Dwivedi Y (2018) Interaction between earlylife stress and FKBP5 gene variants in major depressive disorder and post-traumatic stress disorder: a systematic review and metaanalysis. J Affect Disord 225:422-428

Wilker S, Pfeiffer A, Kolassa S, Elbert T, Lingenfelder B, Ovuga E, Papassotiropoulos A, de Quervain D, Kolassa IT (2014) The role of FKBP5 genotype in moderating long-term effectiveness of exposure-based psychotherapy for posttraumatic stress disorder. Transl Psychiatry 4:e403

Yehuda R (2002) Post-traumatic stress disorder. N Engl J Med 346:108-114

Yehuda R, Daskalakis NP, Desarnaud F, Makotkine I, Lehrner AL, Koch E, Flory JD, Buxbaum JD, Meaney MJ, Bierer LM (2013) Epigenetic biomarkers as predictors and correlates of symptom improvement following psychotherapy in combat veterans with PTSD. Front Psychiatry 4:118

Yehuda R, Pratchett LC, Elmes MW, Lehrner A, Daskalakis NP, Koch E, Makotkine I, Flory JD, Bierer LM (2014) Glucocorticoid-related predictors and correlates of post-traumatic stress disorder treatment response in combat veterans. Interface Focus 4:20140048

Yehuda R, Flory JD, Bierer LM, Henn-Haase C, Lehrner A, Desarnaud F, Makotkine I, Daskalakis NP, Marmar CR, Meaney MJ (2015) Lower methylation of glucocorticoid receptor gene promoter $1 \mathrm{~F}$ in peripheral blood of veterans with posttraumatic stress disorder. Biol Psychiatry 77:356-364

Young DA, Inslicht SS, Metzler TJ, Neylan TC, Ross JA (2018) The effects of early trauma and the FKBP5 gene on PTSD and the HPA axis in a clinical sample of Gulf War veterans. Psychiatry Res 270:961-966

Zannas AS, Provencal N, Binder EB (2015) Epigenetics of posttraumatic stress disorder: current evidence, challenges, and future directions. Biol Psychiatry 78:327-335

Publisher's Note Springer Nature remains neutral with regard to jurisdictional claims in published maps and institutional affiliations. 